\title{
O princípio da precaução nas políticas ambientais globais ${ }^{1}$
}

\section{Precaution in Global Environmental Politics}

\author{
Radoslav S. DIMITROV*
}

\begin{abstract}
RESUMO
O artigo avalia a aplicação do princípio da precaução no nível internacional, utilizando um estudo comparativo de quatro casos nas políticas ambientais globais: erosão da camada de ozônio, chuva ácida, desmatamento e a degradação dos recifes de coral. Contrariamente às noções acadêmicas correntes, $o$ princípio da precaução não é amplamente empregado na política ambiental internacional. Os registros empíricos mostram que os governos se abstêm de implementar uma política de regulamentação quando há incerteza sobre aspectos-chave dos problemas ecológicos. A questão-chave que a literatura tem ignorado é: que tipo de incerteza? De fato, os estados agem mesmo quando a extensão dos problemas ecológicos é desconhecida. Contudo, a incerteza sobre as consequências transfronteiriças de supostos problemas atuam como barreiras à política internacional. Conhecimentos existentes têm subestimado o status do princípio da precaução no direito internacional, subespecificando quando o princípio da precaução é aplicado e sob que tipo de incerteza científica.
\end{abstract}

Palavras-chave: chuva ácida; recifes de coral; desmatamento; política ambiental; ciência ambiental; regimes internacionais; erosão da camada de ozônio; princípio da precaução.

\begin{abstract}
The article evaluates the application of the precautionary principle at the international level. It employs a comparative study of four cases in global environmental politics: ozone depletion, acid rain, deforestation and coral reef degradation. Contrary to widespread academic notions, the precautionary principle is not widely applied in international environmental policy. The empirical record shows that governments abstain from regulatory policy when they face uncertainty about key aspects of ecological problems. The key question that the literature has ignored is: what kind of uncertainty? Indeed, states do take action when the extent of ecological problems is unknown. However, uncertainty about the transboundary consequences of alleged problems prevents international policy. Existing scholarship has misappraised the status of PP in international law, by underspecifying when PP is applied and under what kind of scientific uncertainty.
\end{abstract}

Key-words: acid rain; coral reefs; deforestation; environmental policy; environmental science; international regimes; ozone depletion; precautionary principle.

\footnotetext{
${ }^{1}$ Este artigo foi publicado pela primeira vez no Int. J. Global Environmental Issues sob o título "Precaution in global environmental politics", v. 5, n. 1/2, p.96-113. O tradutor agradece ao professor Radoslav Dimitrov por nos conceder os direitos de tradução e publicação (tradução: Vicente Rosa Alves; revisão: Júlia Spatuzzi Felmanas)

" Professor assistente em Ciência Política pela University of Western Ontario e participa nas negociações ambientais como um analista para o Earth Negociations Bulletin. Sua pesquisa aparece nos seguintes periódicos: International Studies Quarterly, The Journal of Environment and Development and Society and Natural Resources. As ideias neste artigo são mais desenvolvidas em seu próximo livro, Knowledge, Power and Interests in Global Environmental Politics.
} 


\section{Introdução}

Um tema de exploração intelectual permanente na história humana tem sido a relação entre as ideias e o comportamento humano. Numa variedade de contextos temáticos pensadores, por milênios a fio, exploraram a conexão entre conhecimento e ação, entre o mundo ideal e observável. Como o que sabemos afeta o que fazemos? Em que grau o comportamento humano é intencional e racional? Os formuladores de política tomam decisões baseados nas informações de especialistas? Uma das áreas em que estas questões tornam-se particularmente relevantes e altamente consequentes é a gestão ambiental. Neste âmbito, tomadores de decisão e cientistas confrontam-se com as enormes complexidades dos sistemas ecológicos, altos níveis de incerteza e grandes obstáculos para a compreensão científica.

Como as sociedades devem responder aos complexos riscos ambientais quando não existem informações completas sobre eles? Padrões científicos tradicionais exigem altos níveis de correlação estatística e o estabelecimento de ligações causais rigorosas entre causa e efeito. Contra esta experiência, alguns analistas salientam que a ciência muitas vezes é incapaz de prever os graves impactos negativos das substâncias e atividades antropogenicamente geradas ${ }^{2}$ e das atividades sobre a saúde humana e o meio ambiente. Deste ponto de vista, ausência de evidência não é evidência de ausência de dano. Muitos atores enfatizam, além disso, que os impactos ecológicos não podem ser sempre quantificados e que seu timing e magnitude não podem ser previstos com certeza. Esta é a razão por que os partidários do princípio da precaução ${ }^{3}$ (PP) argumentam que as incertezas irredutíveis deveriam ser integradas às decisões gerenciais e que informações incompletas não deveriam impedir a regulamentação ambiental (TICKNER, 2003).

As implicações controversas deste princípio são que as decisões políticas devem ser tomadas sem o apoio total das informações dos especialistas. Este ponto altamente controverso vem produzindo debates acalorados entre vários atores sociais que têm interesse na formulação das políticas ambientais. Discussões nas páginas de vários periódicos, jornais e livros têm sido altamente interdisciplinares, envolvendo filósofos, biólogos, economistas, formuladores de políticas, empregados de corporações e ambientalistas ${ }^{4}$. A maior parte desta literatura é normativa em sua orientação: ela discute os méritos do PP como um guia de política e se as autoridades devem usar o princípio. Trabalhos anteriores abordam o status teórico do princípio, suas implicações éticas, as consequências práticas de segui-lo, se é não científico e como ele se reflete sobre o empreendimento científico natural. Os proponentes chamam a atenção para os méritos da precaução em proteger a saúde humana e ambiental e sustentam que o PP deveria ser adotado como um guia na formulação das políticas (SANDIN et al., 2002; TICKNER, 2003; GOLLIER; TREICH, 2003). Os oponentes sublinham a importância dos fatos que são estabelecidos de forma científica e insistem em rejeitar o PP e basear as políticas em análises tradicionais de custo-benefício e avaliação de risco usando informação disponível (MORRIS, 2000; HAMMITT, 2000).

Este artigo não lida com os debates normativos. Ele está voltado para a questão empírica do que os governos realmente fazem face à incerteza científica sobre os problemas ecológicos. O projeto avalia se os governos aplicam o PP na formulação das políticas ambientais internacionais. As nações se envolvem em ações coletivas regulamentadoras quando elas têm informações incompletas sobre os problemas ecológicos? Mais importante ainda, diante de qual tipo de incerteza elas tomam tal ação política? Essas questões são perseguidas através de uma comparação estruturada de respostas internacionais a quatro problemas ambientais: erosão da camada de ozônio, chuva ácida, desmatamento e degradação dos recifes de coral. Nos dois primeiros casos, os estados alcançaram uma série de acordos jurídicos internacionais. Em contraste, as deliberações sobre o desmatamento e a degradação dos recifes de coral não levaram a regulamentações internacionais.

$\mathrm{O}$ artigo resume as conclusões do projeto comparativo. Para cada um dos quatro casos, eu avalio o grau de incerteza científica sobre o problema ecológico ${ }^{5}$. A análise

\footnotetext{
${ }^{2}$ Anthropogenically-generated substances.

${ }^{3}$ Precautionary principle.

${ }^{4}$ Ver por exemplo números especiais de Foundations of Science, v. 2, 1997; Human and Ecological Risk Assessment, v. 6, n. 3, 2000, e Journal of Risk Research, v. 5 , n. 4 (2002).

${ }^{5}$ Com respeito às fontes de informação científica, a atenção aqui está voltada principalmente para as avaliações científicas multilaterais coordenadas por instituições internacionais. Estas incluem: a articulação de estudos sobre a erosão da camada de ozônio pela Organização Mundial de Meteorologia (OMM) e a The National Aeronautics and Space Administration of the USA (NASA); a pesquisa sobre chuva ácida conduzida pela The International Research Network, que fornece insumos para a Convenção sobre a Poluição Atmosférica Transfronteiras a Longa Distância (LRTAP); as avaliações regulares do Global Forest Resources encomendadas
} 
considera as informações científicas disponíveis em avaliações científicas multilaterais no período em que decisões-chave foram tomadas e distingue entre três aspectos de um problema:

- $\quad$ sua extensão

- $\quad$ suas causas

- $\quad$ suas consequências transfronteiriças.

Cada estudo de caso investiga o estado do conhecimento científico sobre estes aspectos e observa como ele se relaciona com o processo de formulação política internacional. Uma noção refinada do conhecimento nos permite observar que os formuladores de política aplicam o PP seletivamente. Os governos aplicam o PP sob condições de incerteza sobre alguns aspectos do problema, mas exigem informações completas sobre outros. Alguns tipos de informações baseadas em pesquisas ${ }^{6}$ desempenham papéis irregulares na formulação da política internacional.

\section{O princípio da precaução: uma introdução}

O princípio da precaução é geralmente considerado um dos princípios do direito ambiental internacional (TROUWBORST, 2002). Contudo, o princípio não tem uma definição que seja universalmente aceita. Inventários conceituais revelaram pelo menos 19 formulações diferentes (SANDIN, 1999). Contudo, o cerne comum do significado envolve uma relação entre incerteza científica e ação política: quando a eventualidade de uma ameaça ambiental aparece, uma ação preventiva deve ser tomada mesmo quando uma informação científica relevante é incompleta ou duvidosa. O postulado tem uma versão reativa e proativa. Em primeiro lugar, a incerteza científica sobre um problema potencial não deveria impedir os governos de implementar políticas de regulamentação para proteger o meio ambiente e a saúde humana. A Organização para a Cooperação e o
Desenvolvimento Econômicos $(\mathrm{OCDE})^{7}$, por exemplo, declarou que "a ausência de informações completas não deveria impedir a ação preventiva para mitigar o risco de dano significativo para o meio ambiente" 8 . Por outro lado, os governos não deveriam permitir novas substâncias ou atividades - tais como alimentos geneticamente modificados ${ }^{9}$ - se os seus impactos potenciais não são completamente compreendidos. A Carta Mundial da Natureza ${ }^{10}$ (1982), por exemplo, estipula que "onde os efeitos potenciais adversos [das atividades socioeconômicas] não forem completamente compreendidos, as atividades não devem prosseguir". Assim, o PP sugere que a incerteza científica deveria ser tratada ou como uma luz verde para a ação regulamentar ou como uma luz vermelha na encruzilhada das escolhas políticas.

Estudos sobre a história do direito remontam as origens do PP à legislação ambiental nacional da Alemanha e identificaram a lei sobre a poluição do ar de 1976 da República Federal da Alemanha como o primeiro instrumento político a incorporar o PP. AAlemanha também é vista como a primeira a introduzir e promover o conceito no nível internacional durante as negociações com respeito à proteção do Mar do Norte. Gradualmente, o princípio permeou as políticas ambientais regionais e globais, difundindo-se através do direito ambiental setor por setor (TROUWBORST, 2002). Hoje, mais de 50 acordos multilaterais são citados por conter referências à precaução, numa versão ou noutra. Estes incluem a Convenção Internacional sobre a Preparação, o Combate e a Cooperação em Matéria de Poluição por Hidrocarbonetos ${ }^{11}$, a Convenção de Bamako de 1991 para o Controle da Movimentação Transfronteiriça e do Manejo de Resíduos Perigosos na África ${ }^{12}$, a Convenção-Quadro das Nações Unidas sobre Mudança do Clima ${ }^{13}$, a Convenção sobre Diversidade Biológica ${ }^{14}$, a Convenção sobre Poluentes Orgânicos Persistentes ${ }^{15}$ e o Protocolo de Cartagena sobre Biossegurança ${ }^{16}$. Os analistas notaram que,

pela Organização das Nações Unidas para a Alimentação e a Agricultura; e os relatórios da Rede de Monitoramento Global de Recifes de Coral (GCRMN), que compreende um grande número de pesquisadores ao redor do mundo.

${ }^{6}$ Research-derived information.

${ }^{7}$ The Organization for Economic Cooperation and Development (OECD).

${ }^{8}$ OECD Council Recommendation C (90) 164 on Integrated Pollution Prevention and Control, citado por Trouwborst (2002, p. 227-228).

${ }^{9}$ Genetically engineered foods.

${ }^{10}$ The 1982 World Charter for Nature.

11 The International Convention on Oil Pollution.

12 The Bamako Convention on Hazardous Waste.

${ }^{13}$ The Framework Convention on Climate Change.

${ }^{14}$ The Convention on Biological Diversity.

${ }^{15}$ The Convention on Persistent Organic Pollutants.

${ }^{16}$ The Protocol on Biosafety. 
pela metade dos anos 1990, o PP estava sendo incorporado praticamente em cada documento de política internacional relacionado à gestão ambiental (CAMERON, 2001).

\section{Avaliando a aplicação do PP}

A noção de que os governos estão adotando progressivamente o PP nas políticas ambientais internacionais é indiretamente apoiada por muitos estudos que exploram a interface entre ciência e política na arena internacional (ANDRESEN et al., 2000; HAAS, 1992; LITFIN, 1994; SOCIAL LEARNING GROUP, 2001). Estas investigações descobriram que os estados criam regimes políticos a despeito das lacunas significativas de informação e incerteza científica. Cada vez mais, os pesquisadores observam que existem incertezas científicas significativas e lacunas de conhecimento sobre um problema quando os estados se comprometem com acordos jurídicos relacionados a políticas internacionais (HAAS, 1992; LITFIN, 1994). Por exemplo, os pesquisadores sustentam que os tratados internacionais sobre a erosão da camada de ozônio adotam o PP.

De fato, a própria adoção da Convenção de Viena ${ }^{17}$ e do subsequente Protocolo de Montreal de $1987^{18}$ são os principais exemplos da regulamentação ambiental preventiva avant la lettre; já que em meados dos anos 1980 muitas incertezas ainda nublavam a compreensão da influência dos CFCs e outras substâncias sobre a camada de ozônio (TROUWBORST, 2002, p. 23).

Tais conclusões são prematuras e talvez afetadas de forma negativa por uma hipótese analítica problemática. Um problema fundamental em trabalhos anteriores que avaliam a aplicação do PP é que o conhecimento científico é tratado como uma simples entidade unitária. A literatura não presta suficiente atenção às diferenças entre os tipos de informação e como os diferentes tipos de incerteza afetam a ação coletiva. A maior parte, embora nem todos, trata a informação científica como uma variável simples, dicotômica: "conhecimento sobre o problema". Nenhum esforço é feito para especificar: informação sobre qual aspecto do problema?

Esta hipótese de ciência unitária não é realista. A pesquisa ecológica nas ciências naturais é uma tentativa extremamente complexa e multicomponente, que envolve muitas disciplinas acadêmicas distintas: química, física, biologia, meteorologia, geologia, medicina, química atmosférica etc. Conceitualmente, portanto, não é realista presumir a singularidade da "ciência". Além disso, o estado do conhecimento em diferentes áreas não progride uniformemente ou simultaneamente. A variação no tempo do estado e extensão do conhecimento de uma área não equivale à variação do estado e extensão do conhecimento de suas causas e consequências. Não há razão para supor, por exemplo, que os avanços na química atmosférica sobre as medições das concentrações de ozônio acarretariam também progressos na pesquisa médica sobre as consequências para a saúde da erosão da camada de ozônio. Os dois são campos distintos da pesquisa que não andam juntos, mas fazem progresso independentemente um do outro.

Levar em conta a distinção entre os tipos de informação é essencial para avaliar corretamente a aplicação do PP na formulação da política internacional. Esta nova abordagem conduz a diferentes conclusões. No caso da erosão da camada de ozônio, por exemplo, quando o Protocolo-chave de Montreal foi criado, não havia de fato evidências conclusivas sobre a extensão da erosão da camada de ozônio. Havia também alguma incerteza sobre as causas da erosão. No entanto, havia informações confiáveis e um consenso científico sobre as consequências negativas da erosão da camada de ozônio (câncer de pele, cegueira etc.). Os mecanismos através dos quais o aumento da radiação ultravioleta danifica a saúde humana, as plantas terrestres e a vida aquática eram bem conhecidos e nunca foram contestados por cientistas ou negociadores. Este conhecimento amplamente aceito existiu desde o princípio das discussões globais e forneceu uma importante zona de entendimento que facilitou a negociação dos tratados. Isto se torna claro apenas se nós fizermos a distinção entre os tipos de informação. Juntar vários tipos de informação distorce a análise e leva a conclusões tendenciosas com respeito ao lugar do PP na gestão ambiental internacional.

\footnotetext{
${ }^{17}$ The Vienna Convention.

181987 Montreal Protocol.
} 


\section{Quatro relatos de politicas ambientais globais}

\section{Erosão da camada de ozônio ${ }^{19}$}

Em 1974, duas publicações acadêmicas apresentaram uma teoria científica para demonstrar que certos produtos químicos industriais produzidos pelo homem, quando lançados à atmosfera, reduziam as concentrações de ozônio estratosférico tornando, assim, menos delgado o escudo protetor que absorve a radiação ultravioleta do sol. Visto que os resultados do aumento da radiação solar eram conhecidos por serem prejudiciais, acreditava-se que a erosão da camada de ozônio tinha consequências negativas sobre a saúde humana e o sistema imune de plantas e espécies marinhas. Para abordar o problema, o movimento político internacional evoluiu na virada da década e encontrou oposição vinda de companhias que ou produziam ou usavam estas substâncias ${ }^{20}$. Em 1982, através de um pedido formal das nações escandinavas, o Programa das Nações Unidas para o Meio Ambiente (PNUMA) ${ }^{21}$ convocou o primeiro encontro de um comitê para negociar um tratado internacional sobre a erosão da camada de ozônio. As nações ocidentais europeias resistiram fortemente a medidas de controle; enquanto os EUA, as nações escandinavas, Canadá, Áustria e Suíça apoiaram a regulamentação.

Em 1985, depois de anos de deliberações, os governos assinaram um acordo base geral: a Convenção de Viena para a Proteção da Camada de Ozônio ${ }^{22}$. As negociações prosseguiram em dezembro de 1986 para negociar um protocolo para a convenção. As opções políticas apresentadas eram muito diferentes e, até abril de 1987, as nações da Comunidade Europeia não concordariam em mais do que a fixação de um teto na capacidade de produção. Uma solução conciliatória foi alcançada e 24 nações assinaram o Protocolo de Montreal sobre Substâncias que Reduzem a Camada de Ozônio ${ }^{23}$ em setembro de 1987. Este tratado estipulou em $50 \%$ as reduções na produção de muitas substâncias redutoras de ozônio. O regime regulamentar foi reforçado mais adiante por emendas que asseguravam a eliminação completa de todas as principais substâncias redutoras de ozônio até 1996.

\section{A ciência do ozônio ${ }^{24}$}

Diferenças marcantes sobre vários aspectos do problema caracterizaram o estado do conhecimento científico na época das negociações. Havia problemas significativos em medir a extensão das mudanças do ozônio. As medições indicavam um aumento na quantidade de substâncias redutoras de ozônio e havia também um entendimento geral de que menos ozônio significaria mais radiação UV; mas se havia uma verdadeira mudança na camada de ozônio permaneceu uma questão sem respostas seguras até um período depois da assinatura do Protocolo de Montreal. Até o início dos anos 1990, as medições da erosão da camada de ozônio eram consideradas duvidosas (PARSON, 1993, p. 72). Somente antes da preparação do Protocolo de Montreal, um estudo internacional detalhado concluiu: "Nós ainda estamos com poucos dados [...] as medidas não são adequadas para testar criticamente os modelos fotoquímicos" (WMO, 1986, p. 13). A primeira evidência conclusiva de um buraco de ozônio sobre a Antártica apareceu depois que o protocolo foi assinado em Montreal (DIMITROV, 2003).

Do mesmo modo, havia pouca confiança sobre as causas do problema e suas contribuições relativas. Havia várias explicações alternativas sobre a erosão da camada de ozônio que se baseavam em fenômenos naturais, tais como a espuma do mar expelindo átomos de cloro dos oceanos na atmosfera, o papel das partículas de gelo sobre a superfície das nuvens estratosféricas polares e os ciclos solares provocando uma oscilação da radiação e flutuação dos níveis de ozônio (STOLARSKI, 1988). Os cientistas acharam impossível determinar a contribuição precisa das fontes antropogênicas em relação aos fatores naturais. Mesmo em 1989, dois anos após a assinatura do Protocolo, um relatório internacional declarou explicitamente que "os registros atuais são insuficientes para diferenciar os efeitos dos processos naturais daqueles produzidos pelo homem no que diz respeito à erosão da camada de ozônio" e que nenhuma tentativa de fazê-lo foi feita (WMO, 1990, p. ix).

Por outro lado, as consequências potenciais do problema eram conhecidas com segurança e nunca foram

\footnotetext{
${ }^{19}$ Ozone depletion.

${ }^{20}$ O processo de negociações é extensivamente documentado em Litfin (1994) e Benedick (1998).

${ }^{21}$ United Nations Environment Programme.

${ }^{22}$ The Vienna Convention for the Protection of the Ozone Layer.

${ }^{23}$ The Montreal Protocol on Substances that Deplete the Ozone Layer.

${ }^{24}$ Ozone science.
} 
contestadas, seja por cientistas ou por formuladores de política. Os efeitos nocivos da radiação UV eram conhecidos desde o início e não mudaram, em sua essência, ao longo de todos esses anos de pesquisa e discussões. Eles podem ser classificados em três categorias principais: 1) efeitos sobre a saúde humana (câncer de pele, doenças oculares, e supressão do sistema imune $)^{25}$; 2) efeitos sobre plantas terrestres e bactérias; e 3) efeitos sobre a vida marinha. Estes efeitos foram bem documentados numa fase inicial, antes mesmo que começassem as negociações multilaterais sobre a erosão da camada de ozônio, e a informação sobre os efeitos continuou a crescer ao longo dos anos (NRC, 1982).

Os efeitos da exposição excessiva aos raios UV sobre os cânceres de pele resultam de um mecanismo bem conhecido através do qual a radiação solar UV-B danifica o DNA. Vários cânceres de pele (que não são melanomas) tinham sido "inequivocamente associados com a exposição ao sol", incluindo queratoses actínicas pré-malignas, carcinomas basocelulares e carcinomas de células escamosas ${ }^{26}$ (EMMETT, 1986). A radiação ultravioleta pode danificar também muitas partes do olho: a retina, o cristalino, a córnea e os fotorreceptores ${ }^{27}$. O impacto resulta em cataratas, envelhecimento visual, desenvolvimento de deficiência visual em crianças e degeneração da retina ${ }^{28}$. Uma revisão deste tema lista muitos estudos do final dos anos 1970 e começo dos 1980 que demonstram uma associação entre cataratas e exposição à luz UV (WAXLER, 1986). Em 1986, a Agência de Proteção Ambiental dos Estados Unidos ${ }^{29}$ lançou um relatório de 1.600 páginas em cinco volumes intitulado Assessing the Risks of Trace Gases That Can Modify the Stratosphere. Este estudo estimou que o aumento da radiação UV causaria 40 milhões de cânceres adicionais nos próximos 88 anos, 800 mil deles fatais, 12 milhões a mais de cataratas e um número crescente de desordens do sistema imune ${ }^{30}$ (CAGIN; DRAY, 1993, p. 310).

Entre 1975 e 1985, centenas de estudos documentaram os efeitos da radiação ultravioleta sobre as plantas (TERAMURA, 1986b, p. 255). As mudanças resultantes incluem a redução no tamanho da folha, diminuição no peso total e na eficiência do uso da água pela planta. Além disso, em algumas plantas a fotossíntese foi diminuída (TERAMURA, 1986a, p. 170). Consequentemente, estas alterações levaram ao atrofiamento do crescimento das plantas e a um declínio na sua produtividade. As implicações para a agricultura são significativas, porque se constatou que as espécies de plantas mais sensíveis à radiação ultravioleta eram as espécies agrícolas: espécies do feijão, ervilha, repolho e a família da abobrinha (BIGGS; KOSSUTH, 1978). Dezenas de estudos também concluíram que o aumento da luz ultravioleta inflige danos aos plânctons e plantas marinhas que são essenciais à cadeia alimentar aquática. Em 1930, muitas experiências mostraram impactos nocivos da radiação ultravioleta sobre os organismos aquáticos (NRC, 1984). As ramificações deste impacto sobre os fitoplânctons são particularmente amplas porque o fitoplâncton está no fim da cadeia alimentar.

Deste modo, os governos se comprometeram com a implementação de ações coletivas quando estavam seguros com relação às consequências da erosão da camada de ozônio. Com todas as tentativas e erros científicos nas medições do ozônio, ninguém duvidou dos efeitos potenciais nocivos da erosão da camada de ozônio. Visto que havia um conhecimento confiável sobre as consequências do problema, este aspecto da ciência não foi debatido. $\mathrm{O}$ negociador-chefe dos Estados Unidos observa: "Todos estes possíveis efeitos eram conhecidos dos negociadores do Protocolo de Montreal e eles nunca foram seriamente contestados. Era geralmente aceito que as mudanças na camada de ozônio representam sérios riscos para a saúde humana e o meio ambiente". (BENEDICK, 1998, p. 22; grifo nosso).

\section{Chuva ácida}

Do mesmo modo, os governos lidam com o problema da poluição do ar transfronteiriça ${ }^{31}$, geralmente conhecida como chuva ácida, através de uma série de acordos jurídicos internacionais entre as nações europeias e norte-americanas. As emissões industriais frequentes associadas

\footnotetext{
${ }^{25}$ Skin cancer, eye disorders and immune system suppression.

${ }^{26}$ Premalignant actinic keratosis, basal cell carcinomas, and squamous cell carcinomas.

${ }^{27}$ The retina, the crystalline lens, the cornea and the photoreceptors.

${ }^{28}$ Cataracts, visual ageing, impaired visual development in children and retinal degeneration.

${ }^{29}$ The Environmental Protection Agency.

${ }^{30}$ Immune system disorders.

${ }^{31}$ Transboundary air pollution.
} 
com a produção de energia e transporte formam compostos químicos ácidos que caem com a chuva, neve e a cerração ou são diretamente depositados sobre as superfícies. Isto tem muitos impactos negativos sobre os ecossistemas terrestres e aquáticos, incluindo solos, plantas, espécies de água doce e a saúde humana. Nos anos 1960, as pesquisas científicas nas nações escandinavas revelaram que uma parte desta acidificação é possivelmente devida a poluentes que se originam em nações distantes e que o transporte transfronteiriço de emissões ocorre em grande escala. Suécia e Noruega lançaram um apelo pela regulamentação internacional dos poluentes acidificantes e o movimento, pouco a pouco, obteve ímpeto com os governos buscando cada vez mais um tratado.

Em 1979, países da Europa, junto com Canadá e Estados Unidos, criaram o primeiro tratado mundial multilateral para tratar das questões atmosféricas: a Convenção sobre a Poluição Transfronteiriça do Ar de Longo Alcance ${ }^{32}$. No decurso dos anos seguintes, eles construíram um poderoso regime de política internacional que consiste de numerosos acordos para controlar uma variedade de emissões: óxidos de enxofre e nitroso, compostos orgânicos voláteis e poluentes orgânicos persistentes ${ }^{33}$. O primeiro passo regulatório foi o Protocolo sobre a Redução das Emissões de Enxofre ${ }^{34}$, assinado por 21 países em julho de 1985, em Helsinque. O documento estipulou em $30 \%$ os cortes nas emissões e fluxos transfronteiriços de dióxido de enxofre ${ }^{35}$ até 1993 , tendo 1980 como ano-base. Com o Protocolo sobre Óxidos Nitrosos de $1988^{36}$, assinado em Sofia, Bulgária, 25 nações empenharam-se em congelar os níveis de emissões de óxidos nitrosos nos níveis de 1987 até 1994. Em 1999, um Protocolo sobre Compostos Orgânicos Voláteis ${ }^{37}$ foi negociado em Genebra, exigindo uma redução de 30\% dos níveis de emissões de 1988 até 1999. Em junho de 1994, um segundo Protocolo sobre o Enxofre ${ }^{38}$ foi assinado em Oslo por 28 países. Hoje, o regime legal sobre poluição trans- fronteiriça do ar continua a evoluir. Em junho de 1988, as partes criaram dois protocolos sobre metais pesados e sobre poluentes orgânicos persistentes ${ }^{39}$, respectivamente, e estes foram seguidos por um Protocolo de 1999 para a Redução da Acidificação, Eutrofização e Ozônio Troposférico ${ }^{40}$, que impõe emissões-teto mais restritas sobre todos os principais poluentes: enxofre, óxidos nitrosos, Compostos Orgânicos Voláteis e amônia ${ }^{41}$ (LEVY, 1993).

\section{A ciência da chuva ácida ${ }^{42}$}

Característica deste caso é a íntima integração entre as negociações políticas e a acumulação de dados científicos. Um ambicioso processo para a geração de informação foi lançado e, entre 1967 e 1986, havia nada menos do que 6.000 publicações sobre a chuva ácida (SCHINDLER, 1988, nota 4). Muito deste esforço de pesquisa foi iniciado para o estabelecimento do "mais extensivo programa de monitoramento para o acompanhamento de um tratado ambiental" (LEVY, 1993, p. 132). Este processo começou no final dos anos 1970, foi continuamente fortalecido e expandido e tornou-se cada vez mais integrado ao processo político durante os anos 1990. Em 1978, o programa da Organização para a Cooperação e o Desenvolvimento Econômico (OCDE) ${ }^{43}$ evoluiu para o Programa Comum de Vigilância Contínua e de Avaliação do Transporte a Longa Distância dos Poluentes Atmosféricos na Europa $(E M E P)^{44}$. Seu propósito é prover os governos com dados sobre as emissões, concentração e depósito de poluentes e transporte de poluentes de longa distância. O primeiro protocolo sobre o enxofre contém uma cláusula declarando que o acordo deveria ser revisto em intervalos regulares à luz de pesquisas científicas atualizadas.

Nos anos 1970, o conhecimento científico sobre os problemas da acidificação não estava muito avançado.

\footnotetext{
${ }^{32}$ The Convention on Long-Range Transboundary Air Pollution.

${ }^{33}$ Sulphur and nitrous oxides, volatile organic compounds, and persistent organic pollutants.

${ }^{34}$ The Protocol on the Reduction of Sulphur Emissions.

${ }^{35}$ Sulphur dioxide.

${ }^{36}$ The 1988 Protocol on Nitrous Oxides.

${ }^{37}$ Protocol on Volatile Organic Compounds.

${ }^{38}$ Sulphur Protocol.

${ }^{39}$ Protocols on heavy metals and persistent organic pollutants.

${ }^{40} 1999$ Protocol to Abate Acidification, Eutrophication and Ground-Level Ozone.

${ }^{41}$ Sulphur, NOx, VOCs and Ammonia.

${ }^{42}$ Acid rain science

${ }^{43}$ The OECD Programme.

${ }^{44}$ Cooperative Programme for the Monitoring and Evaluation of the Long-Range Transmission of Air Pollutants in Europe (EMEP).
} 
Alguns anos mais tarde, ele progrediu e foi aceito cada vez mais no início dos anos 1980. O EMEP começou a produzir enormes quantidades de dados e, através de métodos cada vez mais sofisticados, tornou possível calcular depósitos em cada país e rastreá-los para fontes localizadas em outros países. "Nesta época [...] não havia dúvidas sobre a natureza transfronteiriça do problema, onde alguns países ganhavam enquanto outros perdiam" (PARK, 1987, p. 177).

A extensão da acidificação da precipitação, água doce e solos podiam ser medidos com precisão e a distribuição geográfica da precipitação ácida era bem conhecida já nos anos 1970 (DRABLOS; TOLLAN, 1980, p. 11). As conclusões de muitos estudos eram sólidas e consistentes: um rápido aumento na acidificação das águas tinha ocorrido desde pelo menos os anos 1940. As evidências de quatro tipos de fontes muito diferentes (teoria geoquímica, análise de tendências de longo prazo, comparações de registros químicos e análises paleoecológicas) demonstraram de forma consistente um aumento da acidificação dos lagos e riachos em áreas norte-americanas e europeias que receberam precipitação ácida (SCHINDLER, 1988).

O conhecimento que se tinha a respeito das causas da acidificação era variável. Por um lado, as reações químicas que convertem óxidos em ácidos eram cientificamente incontestáveis e as emissões podiam ser medidas ou estimadas com precisão. Por outro, a acidificação poderia ser causada por diversos fatores causais naturais, assim como antropogênicos, e suas contribuições relativas não eram conhecidas com segurança. Uma área de incerteza envolvia a chamada relação dose $/$ resposta ${ }^{45}$ : a ligação entre uma unidade de emissões e a quantidade de mudança resultante em acidez. Adversários da regulamentação como, por exemplo, a Central Electricity Generating Board do Reino Unido, argumentavam que a conversão de óxidos em ácidos é tão dependente das condições do tempo que não é certo se as emissões acidificam o meio ambiente (McCORMICK, 1985, p. 19). O que aumentava a acidificação dos lagos era também questão de alguma controvérsia. Os lagos poderiam ser ácidos por causa de condições ecológicas naturais ou por causa de interferência antropogênica. Cada vez mais, as evidências levam a fortalecer a ligação entre poluição transfronteiriça e acidificação, mas as informações sobre as contribuições relativas de diferentes causas permaneciam incompletas.
Havia um consenso generalizado sobre as principais relações de causa-efeito e as consequências potenciais da acidificação. Mesmo em 1970, já se sabia que altas concentrações de óxidos de enxofre e nitrosos e ácidos são tóxicas para as plantas - a única dificuldade era em quantificar os níveis limiares (DRABLOS; TOLLAN, 1980, p. 11). Havia mais incerteza sobre os ecossistemas terrestres (Ibid.). Até 1980, o conhecimento científico sobre os efeitos da chuva ácida sobre os ecossistemas aquáticos era sólido e incontestado. As informações sobre as reações dos peixes à acidificação eram extensivas e a evidência aos danos à vida aquática era rica e consistente (SCHINDLER, 1988).

O impacto da acidificação sobre a saúde humana era potencialmente crítico, mas as evidências eram um tanto confusas. Conhecia-se com segurança que a precipitação ácida era responsável pelo aumento da lixiviação de metais altamente tóxicos - tais como chumbo, cádmio, mercúrio e alumínio - para os solos e águas (HUTCHINSON; HAVAS, 1980, p. 618). Descobriu-se que o alumínio causava demência e vários estudos de diversas partes do mundo associavam isto a uma variedade de doenças neurológicas, incluindo a doença de Lou Gehrig ${ }^{46}$. Por outro lado, alguma incerteza sobre a extensão das doenças que de fato eram causadas pela acidificação prolongou-se até a metade dos anos 1980. Salvo os impactos indiretos da chuva ácida, os efeitos diretos à saúde de altas concentrações de óxido de enxofre (Sox) eram considerados um problema "convencional" de poluição local, em vez de uma parte do problema transfronteiriço da chuva ácida. Apesar de tudo, esses efeitos eram muito sérios e forneciam fortes razões para controlar a acidificação.

Em síntese, havia uma boa compreensão sobre as causas essenciais - relações de efeito e os impactos potenciais da acidificação. As áreas de incerteza pertenciam às medidas quantitativas de impacto, assim como à contribuição relativa da acidificação vis-à-vis outros fatores causais possíveis. Todavia, nenhum cientista parece ter contestado as consequências negativas potenciais da chuva ácida para os solos, a vegetação, a vida aquática e a saúde humana.

Um consenso foi grandemente fortalecido durante a Conferência de Estocolmo sobre Acidificação do Meio Ambiente (1982) ${ }^{47}$, organizado pela Suécia e do qual participou a maior parte dos países europeus. Seu propósito era ouvir uma série de apresentações de pesquisa, refletir

\footnotetext{
${ }^{45}$ Dose/response relationship.

${ }^{46}$ Lou Gerig's disease.

${ }^{47} 1982$ Stockholm Conference on Acidification of the Environment.
} 
sobre o estado do conhecimento existente e consolidar uma compreensão do problema. Mais de 100 especialistas de 20 países produziram uma síntese do estado do conhecimento sobre o problema da acidificação. As conclusões apontaram para uma certeza científica sobre as causas e efeitos do problema: que o aumento da acidificação era devido, principalmente, às emissões industriais de enxofre e nitrogênio; que isto causava mudanças negativas nos ecossistemas e que a redução das emissões levaria, de modo geral, a reduções proporcionais na acidificação (WETSTONE, 1987, p.186). Em 1983, durante uma audiência pública sobre a acidificação no The European Parliament Committee on the Environment, Public Health and Consumer Protection, "todos concordaram que os efeitos adversos da chuva ácida eram claros e o debate não se centrou em se reduzir ou não as emissões, mas em como isto deveria ser feito e quem deveria pagar por isto" (PARK, 1987, p. 174). Os Estados que escolheram se associar ao primeiro protocolo sobre o enxofre tinham aceitado as evidências científicas. Aqueles que escolheram ficar de fora (tais como Polônia e Espanha) não rejeitaram a ciência, mas explicaram sua oposição com outras considerações, tais como os grandes custos econômicos da regulamentação. Apenas os Estados Unidos e o Reino Unido reivindicaram que mais pesquisas precisavam ser feitas (McCORMICK, 1989, p. 85) - uma linha de conduta que parece fazer parte dos procedimentos de funcionamento padrão das delegações dos Estados Unidos em todos os fóruns ambientais internacionais nos últimos anos.

\section{Degradação florestal ${ }^{48}$}

Apesar do apoio popular para deter o desmatamento e apesar do consenso entre os governos com respeito às insustentáveis taxas de degradação florestal, as negociações em vários fóruns internacionais têm falhado, de forma consistente, em produzir um acordo jurídico. A ideia para uma convenção florestal global emergiu no final dos anos 1980 e os anos 1990 viram uma série impressionante de iniciativas estatais globais e regionais para introduzir políticas inter- nacionais de manejo florestal sustentável. As negociações internacionais sobre um tratado florestal ocorreram dentro de três cenários institucionais high-profile: 1) em 1992 na Conferência das Nações Unidas sobre Meio Ambiente e Desenvolvimento (CNUMAD) ${ }^{49}$, no Rio de Janeiro; 2) em quatro sessões do Painel Intergovernamental para as Florestas (IPF) ${ }^{50}$, entre 1995 e 1997, e 3) durante quatro rodadas do Fórum Intergovernamental para as Florestas $(\mathrm{IFF})^{51}$, entre 1997 e 2000.

Na preparação para a CNUMAD, os países industrializados tentaram iniciar as negociações sobre uma convenção florestal global, mas não foram bem sucedidos graças a uma oposição acordada pelos países em desenvolvimento. Em 1995, os estados deram início a um processo de dois anos sob a direção do Painel Intergovernamental para as Florestas para discutir prioridades e opções políticas com respeito ao manejo florestal. Contratempos importantes com respeito à política internacional e uma aparente falta de progresso moveram os governos a continuar as discussões depois de 1997 sob a direção de um novo corpo institucional, o Fórum Intergovernamental para as Florestas (IFF). Depois de oito rodadas de negociações, os estados não alcançaram um acordo sobre a necessidade de uma convenção florestal global e, em 2000, decidiram criar um Fórum das Nações Unidas para as Florestas ${ }^{52}$ não obrigatório, que não tem um mandato para a formulação de políticas (DIMITROV, 2003; LIPSCHUTZ, 2001).

\section{Ciência florestal ${ }^{53}$}

As avaliações científicas internacionais fornecem informações razoavelmente boas sobre a cobertura florestal global e a taxa de desmatamento, assim como uma boa compreensão sobre as principais causas do desmatamento. Contudo, há uma acentuada escassez de informação sobre os benefícios não florestais (isto é, que não estão relacionados com o corte de madeira) das florestas e sobre as consequências do desmatamento. Existe mais controvérsia sobre os efeitos transfronteiriços, compartilhados do desmatamento. Os relatórios multilaterais admitem, de forma

\footnotetext{
${ }^{48}$ Forest degradation.

${ }^{49}$ The 1992 UN Conference on the Environment and Development (UNCED).

${ }^{50}$ The Intergovernmental Panel on Forests (IPF).

${ }^{51}$ The Intergovernmental Forum on Forests (IFF).

${ }^{52}$ United Nations Forum on Forests.

${ }^{53}$ Forest science.
} 
explícita, que os efeitos globais sobre a mudança no clima e na biodiversidade não podem ser medidos com nenhum grau de precisão $0^{54}$.

As avaliações fornecem dados extensivos e precisos sobre a extensão do desmatamento. Um estudo da Organização das Nações Unidas para Alimentação e a Agricultura $(\mathrm{FAO})^{55}$ concluiu que entre 1980 e 1990 as florestas globais e outras terras arborizadas tinham diminuído a uma taxa anual de $0.02 \%$ (FAO, 1995, p. 7-8). Há também um entendimento geral de que as principais causas da degradação florestal são as atividades humanas: extração madeireira, agricultura, pastagem, programas de assentamento, projetos de mineração e hidrelétricos - tais como a construção de barragens e atividades militares. Contudo, há uma acentuada escassez de dados sobre os benefícios não florestais das florestas e as consequências correspondentes do desmatamento. Uma revisão das pesquisas existentes conclui, de forma inequívoca, que a informação sobre os produtos não florestais e as funções das florestas encontra-se num nível rudimentar e que os problemas com sua estimativa e quantificação são preponderantes (NILSSON, 1996).

Relatórios abrangentes da FAO reconhecem incertezas com respeito ao impacto do desmatamento sobre a diversidade: "a magnitude de tais perdas ou a extensão da degradação da biodiversidade é desconhecida" (FAO, 1997, p. 41). Finalmente, as avaliações concluíram que é difícil tirar conclusões dos dados disponíveis. A FAO reconhece que "as necessidades essenciais dos pesquisadores e formuladores de políticas não puderam ser realizadas satisfatoriamente" (FAO, 1995, p. 41). Além disso, avaliações multilaterais declaram, de forma explícita, que "é pouco provável que seja possível, num futuro próximo, fazer inventários abrangentes de bens e serviços não florestais a nível global" (FAO, 1995, p. 30).

A ausência de informação confiável sobre as consequências transfronteiriças do desmatamento ajudou a moldar as posições de negociação dos estados e afetou os debates internacionais em várias etapas. Muitos países rejeitaram a ideia das florestas como um bem público. Na Conferência do Rio, em 1992, os países em desenvolvimento sustenta- vam que, visto que o problema é essencialmente local por natureza, ele está sujeito às políticas e legislação nacionais e não é uma questão de obrigações internacionais. $\mathrm{O}$ ministro brasileiro do Meio Ambiente, José Goldenberg, declarou que o Brasil não via necessidade para uma convenção internacional, a menos que as incertezas sobre as emissões de gases do efeito estufa fossem dissipadas. Oito anos mais tarde, Everton Vargas, principal negociador do Brasil no Fórum Intergovernamental para as Florestas - 4 (IFF-4), concordou: "as florestas não são propriedades públicas globais; elas são recursos nacionais". O delegado norte-americano do encontro de especialistas em Ottawa e mais tarde um negociador no IFF-4 declarou, na verdade, que "as florestas são inerentemente locais; elas não são propriedades públicas globais. Os efeitos em rede [do desmatamento] são muito fragmentados" ${ }^{\prime 6}$. De modo notável, nenhuma delegação fez objeção a tais declarações (DIMITROV, 2003).

\section{Recifes de coral $^{57}$}

Preocupações sobre as condições dos sistemas de coral foram manifestadas em muitos fóruns internacionais, tais como: no contexto da Convenção sobre Diversidade Biológica, na Convenção-Quadro das Nações Unidas sobre Mudança do Clima, na Convenção sobre o Comércio Internacional das Espécies da Fauna e da Flora Ameaçadas de Extinção ${ }^{58}$ e na Conferência das Nações Unidas sobre o Desenvolvimento Sustentável das Pequenas Ilhas ${ }^{59}$. Porém, não há um regime de política internacional para coordenar a gestão dos recifes de coral. Um desenvolvimento de política a nível internacional é a International Coral Reef Iniciative (ICRI), que surgiu de preocupações que foram manifestadas na conferência de Barbados para o desenvolvimento sustentável das pequenas ilhas ${ }^{60}$, em 1993. A ICRI é uma ampla parceria de governos, bancos de desenvolvimento internacionais, ONGs, cientistas e setor privado. Não é nem uma estrutura de governança global nem um corpo de formuladores de política. É uma rede informal de partes interessadas, um fórum aberto para

\footnotetext{
${ }^{54}$ Uma análise extensiva e detalhada das informações científicas disponíveis com respeito ao desmatamento é feita em Dimitrov (2003, 2004).

${ }_{55}$ The Food and Agriculture Organization (FAO).

${ }^{56}$ Jan MacAlpine, Senior Forest Officer, US State Department, Office of Ecology and Terrestrial Conservation. Entrevistado em 11 de dezembro de 1999.

${ }^{57}$ Coral reefs.

${ }^{58}$ The Convention on International Trade of Endangered Species.

${ }^{59}$ The Global Conference on Sustainable Development of Small Island Developing States.

${ }^{60}$ Conference of Small Island States in Barbados.
} 
atores políticos discutirem questões relativas aos recifes de coral, partilharem informação, promoverem pesquisa e identificarem prioridades políticas. A iniciativa não tem uma estrutura ou organização burocrática permanente e não se envolve com a ação: não desenvolve, não financia, nem implementa política (DIMITROV, 2002).

\section{Ciência dos recifes de coral ${ }^{61}$}

Apesar do impressionante número de atividades de pesquisa nas quais milhares de cientistas estão envolvidos, o conhecimento existente sobre todos os três aspectos da degradação dos recifes de coral é caracterizado como incerto. Embora pesquisadores e ativistas tenham uma clara sensação de que os recifes de coral estão enfrentando um declínio que é, pelo menos em parte, impulsionado pelas atividades humanas e que tem consequências indesejáveis, a ciência dos corais não progrediu o suficiente para fornecer ou detalhes ou dados confiáveis sobre a reação dos corais ao stress, suas perspectivas de adaptação ou o impacto ecológico e social da degradação dos recifes. Enquanto algumas destas lacunas devem-se à escassez de financiamento e poderiam ser preenchidas com mais monitoramento, outras lacunas de informação existem graças a importantes limitações para a compreensão científica que, muito provavelmente, não poderiam ser resolvidas no curto prazo.

Na metade dos anos 1990, várias revisões de documentos indicaram que um conhecimento abrangente sobre a saúde e o valor dos recifes de coral encontra-se praticamente ausente (BRYANT et al., 1998). Antes de 1998, a única informação sobre o status dos recifes era uma estimativa amplamente citada "baseada em adivinhações de vários cientistas e em fontes não confirmadas" (BRYANT et al., 1998, p. 7) de que $10 \%$ dos recifes estavam mortos e que outros $30 \%$ estariam provavelmente mortos dentro de 10 a 20 anos (WILKINSON, 1993). Em resposta à evidente necessidade de dados, em 1996 a Comissão Oceanográfica Internacional ${ }^{62}$, o Programa das Nações Unidas para o Meio Ambiente (PNUMA), o Banco Mundial e a União Internacional para a Conservação da Natureza e dos Recursos Naturais (IUCN) ${ }^{63}$ formaram uma parceria para estabelecer uma Rede de Monitoramento Global de Recifes de Coral
$(\mathrm{GCRMN})^{64}$. O objetivo desta rede é coletar, sintetizar e disseminar informações sobre a saúde dos recifes de corais e ajudar as comunidades e os estados a construir capacidade de pesquisa para a avaliação dos corais.

A primeira avaliação global sobre a verdadeira condição dos corais foi realizada pela já mencionada rede de monitoramento (GCRMN) através da publicação do relatório Status of Coral Reefs of the World: 1998. Ele foi considerado a primeira estimativa confiável da condição global dos recifes. Curiosamente, em lugar de fazer soar o alarme, o relatório pareceu bastante otimista: no sumário executivo, os autores revelaram que "a maior parte dos recifes de coral do mundo estão em boa ou excelente condição porque eles estão ou distantes das populações humanas ou sob boa gestão [...]". Além disso, o relatório ainda informa que os recifes que já estavam danificados podiam ter altas chances de recuperação: “Afortunadamente, a maior parte dos recifes tem alta capacidade para se recuperar e, se as pressões forem reduzidas ou removidas, muitos recifes danificados retornarão a um status saudável”. Apenas dois anos mais tarde, um segundo relatório da rede de monitoramento (GCRMN), Status 2000, teve um tom mais pessimista. Ele concluiu que $27 \%$ dos recifes do mundo estavam perdidos, que apenas em 1998 16\% foram destruídos e que "provavelmente metade destes nunca se recuperarão adequadamente". Este segundo relatório também fez prognósticos de que $40 \%$ dos recifes desaparecerão até 2010 e os outros $20 \%$ 20 anos mais tarde.

O conhecimento sobre as causas do problema poderia ser avaliado como moderadamente suficiente. Cientistas envolvidos em pesquisas sobre os recifes de coral compartilham um consenso geral sobre um conjunto de fatores que contribuem para o seu declínio (KNOWLTON, 2001). Estes podem ser agrupados em três categorias: 1) causas naturais, 2) causas humanas indiretas e 3 ) causas humanas diretas. Os recifes de coral podem ser danificados por tensões naturais graves, tais como furacões, tufões, terremotos subaquáticos, vulcões submarinos, doenças e eclosão de pragas. Todas as principais avaliações, contudo, focalizam-se sobre os fatores humanos diretos. O relatório de avaliação global Reefs at Risk considera o desenvolvimento costeiro, a superexploração, a poluição e erosão de áreas terrestres e a poluição marítima como os principais fatores que ameaçam a saúde

\footnotetext{
${ }^{61}$ Reef Science.

${ }^{62}$ The Intergovernmental Oceanographic Commission.

${ }^{63}$ The World Conservation Union.

${ }^{64}$ Global Coral Reef monitoring Network (GCRMN).
} 
dos corais. Ao mesmo tempo, as contribuições relativas de causas particulares permanecem indeterminadas. Além disso, diferentes avaliações científicas ao longo dos anos 1990 ofereceram classificações conflitantes das causas da degradação dos recifes, com um deslocamento geral das causas locais para fatores regionais e globais.

A característica mais estarrecedora do conhecimento compartilhado sobre os recifes de coral é a completa ausência de informação sobre as consequências da sua degradação. Relatórios de avaliações multilaterais abrangentes não dizem nada sobre os impactos socioeconômico e ecológico do problema. Não apenas tal informação está ausente dos relatórios disponíveis, mas nenhum esforço ostensivo é exercido para estudar este aspecto do problema. A composição da rede de monitoramento (GCRMN) é indicativa a este respeito: ela envolve muitos cientistas biólogos e físicos, mas não cientistas sociais para fornecer análises econômicas de vários cenários para o uso dos recifes de coral. Como o seu coordenador prontamente reconhece, a rede de monitoramento (GCRMN) focaliza-se exclusivamente sobre a extensão e as causas do declínio dos corais, mas não procura ainda fornecer informação sobre as consequências destes problemas para as comunidades humanas (WILKINSON, comunicação pessoal) ${ }^{65}$.

Isto não quer dizer que a degradação dos recifes de coral não seja considerada um problema. Artigos em revistas populares e declarações políticas fazem, regularmente, referência ao importante papel dos recifes de corais, alertando para as sérias consequências de seu declínio. Entretanto, avaliações multilaterais são inteiramente desprovidas de qualquer estimativa específica dos valores ecológicos e socioeconômicos dos recifes e do impacto correspondente de seu declínio. Somente um relatório tenta enfocar os efeitos da degradação dos recifes de coral, apenas para reconhecer explicitamente a escassez de tais dados. Em relação à bio- diversidade, por exemplo, o relatório de avaliação global Reefs at Risk informa que faltam informações a respeito deste assunto: "especialistas mal começaram a catalogar o número total de espécies encontradas dentro dos [recifes] habitats" e mesmo a mais rudimentar das estimativas varia (BRYANT et al., 1998, p. 8).

Assim, as informações existentes sobre os recifes de coral, não retratam a sua degradação como uma questão global que envolve interdependência e não oferecem razões claras para a ação coletiva através de um sistema de obrigações de estado-para-estado. Até mesmo os ativistas comprometidos com a preservação dos corais não julgam necessário um tratado internacional. De fato, nenhum estado exigiu negociações para um tratado. E nenhum grupo social, exceto os cientistas e ativistas ambientais, defendeu uma política regulatória (DIMITROV, 2002).

\section{Sumário das conclusões}

As conclusões deste projeto são baseadas em análises comparativas de quatro casos. As conclusões empíricas estão sumarizadas na tabela abaixo.

Comum a ambos os casos de formação de regimes bem sucedidos (ozônio e chuva ácida) foi o alto grau de consenso científico sobre as consequências transfronteiriças do problema. Isto envolveu informação confiável sobre os efeitos negativos dos problemas ecológicos, assim como a certeza de que estes efeitos poderiam ocorrer em outros países além daqueles onde os efeitos se originaram. Com respeito à chuva ácida, havia um consenso científico sobre o impacto negativo da acidificação sobre os sistemas aquáticos, suprimentos de água e a saúde humana. Igualmente, as consequências da erosão da camada de ozônio eram um assunto de consenso científico. Os mecanismos por meio dos

TABELA 1 - SUMÁRIO DAS CONCLUSÕES EMPÍRICAS.

\begin{tabular}{lccc}
\hline \multicolumn{4}{c}{ Conhecimento de: } \\
\hline Casos & $\begin{array}{c}\text { Consequências } \\
\text { transfronteiriças }\end{array}$ & $\begin{array}{c}\text { Extensão do Problema } \\
\text { Causas do Problema }\end{array}$ & Médio \\
\hline Regime do ozônio & Média-alta & Baixo & Alto \\
$\begin{array}{l}\text { Regime da chuva ácida } \\
\text { Florestas (ausência de regime) }\end{array}$ & Baixa & Alto & Alto \\
$\begin{array}{l}\text { Recifes de coral (ausência de } \\
\text { regime) }\end{array}$ & Baixa & Médio & Médio \\
\hline
\end{tabular}

${ }^{65}$ Clive Wilkinson, Coordenador da Rede de Monitoramento Global de Recifes de Coral. Entrevistado em 2 de novembro de 2000. 
quais o aumento da radiação UV danifica a saúde humana, plantas terrestres e a vida aquática eram bem entendidos e nunca foram contestados, seja por cientistas ou por negociadores. Por outro lado, ambos os casos de inação coletiva (sobre florestas e os recifes de coral) são caracterizados pela incerteza sobre as consequências transfronteiriças dos problemas. Avaliações multilaterais produziram informação sólida sobre a extensão e as causas da degradação florestal e sobre o declínio dos recifes de coral. Mas havia uma grave escassez de dados sobre os seus efeitos transfronteiriços. A maior parte dos impactos conhecidos está confinada aos níveis locais e nacionais.

A conclusão-chave é que os governos não aplicam o PP face a incerteza sobre as consequências transfronteiriças do problema. A informação sobre as consequências transfronteiriças de um problema parece ser uma exigência importante para a formulação da política ambiental. Há uma clara correspondência entre o estado do conhecimento sobre as dimensões transfronteiriças de um fenômeno e as dinâmicas globais e os processos de formação de regime. O conhecimento seguro e amplamente aceito sobre os impactos compartilhados da erosão da camada de ozônio e da chuva ácida serviram como um ponto focal nas discussões de política internacional destes problemas ecológicos. Ele forneceu uma base constante para negociações e criou zonas de entendimento. Inversamente, quando boas informações sobre os efeitos negativos transfronteiriços estão faltando (como no caso da degradação das florestas e dos recifes de coral), esta lacuna dificulta intensamente o processo e pode impedir a formação de acordos internacionais (DIMITROV, 2002; 2003). Visto que tais impactos transfronteiriços dos dois problemas não são conhecidos com certeza, os benefícios que um país colheria com a proteção das florestas e dos recifes de corais em outras nações permanecem obscuros. Este tipo de incerteza reduz incentivos para criar tratados internacionais e diminui a disposição dos países em se comprometer mutuamente durante discussões políticas.

As evidências apoiam a noção de que os governos aplicam o PP quando existe incerteza sobre a extensão de um problema ecológico - quando se espera que este problema tenha sérias consequências. O modelo indica, de forma clara, que a informação completa sobre a extensão precisa não é uma condição necessária para a formação de um regime político. Tomadores de decisão aceitam um alto grau de incerteza com respeito à exata magnitude de um problema e podem tomar decisões políticas de grande custo mesmo na ausência de tal conhecimento. Para usar a linguagem da causalidade, este tipo particular de informação não é suficiente e nem mesmo necessário para a formação de regime. Por um lado, os estados criaram um regime político forte para abordar a erosão da camada de ozônio, apesar da falta de evidência conclusiva da extensão desta erosão. Por outro, os estados falharam em formar regimes sobre as florestas e os recifes de corais, apesar da disponibilidade de dados sólidos sobre as altas taxas de desmatamento e a extensão do declínio dos recifes de corais.

Os casos também demonstram, de maneira menos inequívoca, que o PP às vezes é utilizado quando existe incerteza sobre as causas de um problema, embora o modelo aqui não seja tão claro. Por um lado, a informação completa sobre as causas de um problema não parece ser uma exigência essencial para a cooperação internacional. Os estados agem sem ter uma estimativa precisa sobre as contribuições relativas de diferentes fatores causais. A erosão da camada de ozônio e a acidificação, por exemplo, são causadas por vários processos naturais, assim como por substâncias fabricadas pelo homem. Quando os estados comprometeram-se com a ação coletiva, os cientistas não podiam determinar qual era a contribuição relativa destas substâncias comparada às causas naturais. Ao mesmo tempo, contudo, um bom conhecimento sobre as causas particulares de origem humana é necessário antes que a ação política possa ser empreendida. A importância deste tipo de informação refere-se principalmente ao desenho de política, porque só o conhecimento da causa de um problema é que permitirá aos atores identificar possíveis políticas que possam melhorá-lo. Caso contrário, como os atores saberiam quais atividades humanas regular e quais emissões controlar? Esta é a razão por que este tipo de conhecimento poderia afetar o conteúdo político essencial de um regime.

\section{Observações finais}

Os governos utilizam o PP e tomam decisões políticas de alto custo apesar da incerteza e/ou informação incompleta. É crucial enfatizar, contudo, que tal incerteza diz respeito apenas a aspectos particulares de problemas ecológicos: a extensão precisa do problema e as contribuições relativas de suas causas. Outros tipos de incerteza, contudo, tem o efeito oposto e dificultam a formação de política. Em particular, as lacunas de informação sobre as consequências ecológicas e sócio-econômicas de um problema são claramente nocivas aos esforços de formação de um regime internacional. 
As conclusões sugerem que os processos de formação de política internacional ostentam um grau significativo de racionalidade em larga escala, pelo menos no longo prazo. Eles retratam a cooperação internacional como uma atividade cuja intenção é a resolução de problemas. Mesmo os críticos da teoria da escolha racional concordam que os atores procuram se beneficiar de suas próprias ações. Portanto, segundo a mais básica noção de racionalidade, a expectativa de utilidade é necessária para a ação. A utilidade de uma política regulatória está em prevenir ou melhorar as consequências negativas do problema. A fim de avaliar os riscos com respeito a um desenvolvimento ecológico, os atores procuram saber quais as consequências que este desenvolvimento pode ter. Informação confiável sobre o impacto de um problema representa um papel integral neste processo, permitindo aos atores cálculos utilitários. De fato, o próprio ato de definir algo como um "problema" pressupõe, e está baseado, em impactos negativos. Um acontecimento particular, tendência ou desenvolvimento é percebido como um "problema" apenas em virtude de suas consequências indesejáveis.

A informação sobre as consequências transfronteiriças é importante também porque fornece os elementos de interdependência. Os regimes de política internacional são respostas coletivas a problemas transnacionais que não podem ser gerenciados efetivamente de uma maneira unilateral. O que torna um problema transnacional é definido por suas consequências transfronteiriças. Portanto, a formação de interesses comuns que se originam da percepção de uma interdependência depende de informação confiável sobre o impacto transfronteiriço de um suposto problema.

Alguns leitores estão menos interessados nas teorias da política internacional e mais preocupados com a degradação ambiental e a necessidade de uma política ambiental imediata e bem desenhada nos níveis nacional e internacional. Exceto por sua importância teórica, o estudo oferece insights que podem ser úteis aos formuladores de políticas e cientistas naturais que estão interessados nos modos de fortalecer a interface entre a política e as ciências e na otimização do uso da pesquisa científica na formação de políticas. A recomendação para os formuladores de políticas que extraem as lições deste estudo é para avaliarem cuidadosamente o estado do conhecimento especializado sobre as consequências de um problema antes deles embarcarem em iniciativas de política internacional. $\mathrm{O}$ caso das florestas, em particular, fornece um duro exemplo da futilidade dos esforços políticos quando as informações nas quais se baseia a tomada de decisão não são adequadas.

O estudo também oferece recomendações sobre onde focalizar a pesquisa científica sobre os problemas ecológicos, de maneira que fortaleçam os esforços para introduzir uma política ambiental responsável. Ao nível mundial, muitos biólogos, químicos, cientistas da atmosfera e outros cientistas naturais tentam ajudar a formação de políticas e ficam frequentemente frustrados quando os formuladores de políticas não consideram atentamente seus investimentos. Enormes quantias de dinheiro são investidas de forma regular em pesquisa científica nos níveis nacional e multilateral. Quanto à mandated research - cujo propósito explícito é fornecer insumos para os formuladores de políticas e ajudá-los a tomar decisões -, o desenho e os objetivos das avaliações científicas tornam-se importantes. Em particular, as avaliações científicas devem focar-se nas pesquisas sobre as consequências dos problemas ecológicos. Como o caso dos recifes de coral ilustra muito claramente, mesmo as avaliações científicas ambiciosas têm pouca chance de facilitar a política ambiental se seus desenhos omitirem a pesquisa sobre as consequências do problema. Quando não há informação conclusiva sobre o impacto transfronteiriço de um "problema", então talvez nenhum esforço deveria ser desperdiçado na discussão de tratados internacionais.

\section{Agradecimentos}

Sou grato a Martin Sampson, Richard Price, Robert Holt, Raymond Duvall e a todos os participantes do The Minnesota International Relations Colloquium pelos seus valiosos comentários e apoio a este projeto. $\mathrm{O}$ financiamento para este estudo teve o apoio do The Institute for the Study of World Politics e da The MacArthur Foundation. 


\section{Referências}

ANDRESEN, S.; SKODVIN, T.; UNDERDAL, A.; WETTESTÄD, J. Science and Politics in International Environmental Regimes: Between Integrity and Involvement. New York: Manchester University Press, 2000.

BENEDICK, R. E. Ozone Diplomacy: New Directions in Safeguarding the Planet, 2nd edition. Cambridge, MA: Harvard University Press, 1998.

BIGGS, R. H.; KOSSUTH, S. V. Effects of ultraviolet-B radiation enhancements under field conditions. UV-B Biological and Climatic Effects Research. Final report, 1978.

BRYANT, D.; BURKE, L.; McMANUS, J.; SPALDING, M. (Eds.). Reefs at Risk. A Map-Based Indicator of Threats to the World's Coral Reefs. Washington, DC: World Resources Institute, 1998.

CAGIN, S.; DRAY, P. Between Earth and Sky. New York: Pantheon Books, 1993.

CAMERON, J. The precautionary principle in international law. In: O'RIORDAN, T.; CAMERON J.; JORDAN, A. (Eds.). Reinterpreting the Precautionary Principle. London: Cameron May, 2001.

DIMITROV, R. S. Confronting non-regimes: science and international coral reef policy. Journal of Environment and Development, v. 11, n. 1, p. 53-78, 2002.

Knowledge, power and interests in environmental regime formation. International Studies Quarterly, v. 47, n. 1, p. 123-150, 2003.

Lost in the woods: international forest policy. In: HARRISON, N. E.; BRYNER, G. C. (Eds.). Science and Politics in the International Environment. Boulder, $\mathrm{CO}$ : Rowman and Littlefield, p. 173-202, 2004.

DRABLOS, D.; TOLLAN, A. (Eds.). Ecological impact of acid precipitation. INTERNATIONAL CONFERENCE. Proceedings... Sandefjord, Norway, May 11-14. Oslo, Norway: SNSF, 1980.

EMMETT, E. Health effects of ultraviolet radiation, In: TITUS, J. (Ed.). Effects of Changes in Stratospheric Ozone and Global Climate. Washington, DC: US EPA and UNEP, p. 129-146, 1986.

FAO (Food and Agriculture Organization). Forest resources assessment 1990: global synthesis. FAO Forestry Paper 124. Rome: FAO, 1995.
. State of the World's Forests. Rome: FAO, 1997.

GOLLIER, C.; TREICH, N. Decision-making under scientific uncertainty: the economics of the precautionary principle. The Journal of Risk and Uncertainly, v. 27, n. 1, p. 77-103, 2003.

HAAS, P. M. (Ed.). Knowledge, Power and International Policy Coordination. Special Issue of International Organization, v. 46, n. 1, 1992.

HAMMITT, J. K. Global climate change: benefit-cost analysis vs. the precautionary principle. Human and Ecological Risk Assessment, v. 6, n. 3, p. 387-398, 2000.

HUTCHINSON, T. C.; HAVA, M. (Eds.). Effects of acid precipitation on terrestrial ecosystems. In: NATO CONFERENCE ON EFFECTS OF ACID PRECIPITATION ON VEGETATION AND SOILS. Proceedings... Toronto, May 1978. New York: Plenum Press, 1980.

KNOWLTON, N. The future of coral reefs. Proceedings of the National Academy of Sciences, v. 98, n. 10, p. 5419-5425, 2001.

LEVY, M. A. European acid rain: the power of tote-board diplomacy. In: HAAS, P. M.; KEOHANE, R. O.; LEVY, M. A. (Eds.). Institutions for the Earth: Sources of Effective International Environmental Protection. Cambridge, MA: MIT Press, p. 75-132, 1993.

LIPSCHUTZ, R. D. Why is there no international forestry law? An examination of international policy regulation, both public and private. UCLA Journal of Environmental Law and Policy, v. 19, p. 155-182, 2001.

LITFIN, K. T. Ozone Discourses: Science and Politics in Global Environmental Cooperation. New York: Columbia University Press, 1994.

McCORMICK, J. Acid Earth: The Global Threat of Acid Pollution. London: Earthscan, 1985.

MORRIS, J. (Ed.). Rethinking Risk and the Precautionary Principle. Oxford: Butterworth Heinemann, 2000.

NILSSON, S. Do we have enough forests? IUFRO Occasional Paper N. 5. Vienna, Austria: International Union of Forest Research Organizations, 1996.

NRC. Causes and Effects of Stratospheric Ozone Reduction: An Update. Washington, DC: National Academy of Sciences, 1982. 
Causes and Effects of Changes in Stratospheric Ozone: Update 1983. Washington, DC: National Academy of Sciences, 1984.

PARK, C. Acid Rain - Rhetoric and Reality. London: Methuen, 1987.

PARSON, E. Protecting the ozone layer. In: HAAS, P.M.; KEOHANE, R.O.; LEVY, M.A. (Eds.). Institutions for the Earth: Sources of Effective International Environmental Protection. London: The MIT Press, p. 27-73, 1993.

SANDIN, P. Dimensions of the precautionary principle. Human and Ecological Risk Assessment, v. 5, n. 5, p. 889-907, 1999.

; PETERSON, M.; HANSSON, S. O.; RUDÉN, C.; JUTHE, A. Five charges against the precautionary principle. Journal of Risk Research, v. 5, n. 4, p. 287-299, 2002.

SCHINDLER, D. W. Effects of acid rain on freshwater ecosystems. Science, v. 239, n. 4836, p. 149-157, 1988.

SLC (SOCIAL LEARNING GROUP). Learning to Manage Global Environmental Risks. Cambridge, MA: MIT Press, 2001.

STOLARSKI, R. The Antarctic ozone hole. Scientific American, v. 258, p. 30-36, 1988.

TERAMURA, A. H. Overview of our current state of knowledge of UV effects on plants, In: TITUS, J. (Ed.). Effects of Changes in Stratospheric Ozone and Climate Change, Washington, DC: UNEP/EPA, v. 1, p. 165-173, 1986 a.
. The potential consequences of ozone depletion upon global agriculture. In: TITUS, J. (Ed.). Effects of Changes in Stratospheric Ozone and Climate Change, Washington, DC: UNEP/EPA, v. 2, p. 255-262, 1986 b.

TICKNER, J. A. (Ed.). Precaution, Environmental Science and Preventive Public Policy. Washington, DC: Island Press, 2003.

TROUWBORST, A. Evolution and Status of the Precautionary Principle in International Law. The Hague: Kluwer Law International, 2002.

WAXLER, M. Ozone depletion and ocular risks from ultraviolet radiation. In: TITUS, J. (Ed.) Effects of Changes in Stratospheric Ozone and Climate Change, Washington, DC: UNEP/EPA, v. 1, p. 147-164, 1986.

WETSTONE, G. A history of the acid rain issue. In: BROOKS, H.; COOPER, C. L. (Eds.). Science for Public Policy. Oxford, UK: Pergamon Press, p. 163-195, 1987.

WILKINSON, C. Coral reefs are facing widespread devastation. In: THE $7^{\text {th }}$ INTERNATIONAL CORAL REEF SYMPOSIUM. Proceedings... Guam, p. 11-12, 1993.

WMO (WORLD METEOROLOGICAL ORGANIZATION). Atmospheric Ozone 1985. Assessment of Our Understanding of the Processes Controlling Its Present Distribution and Change. Report N. 16 of the Global Ozone Research and Monitoring Project. Geneva, Switzerland: WMO, 1986.

. Scientific Assessment of Stratospheric Ozone: 1989,

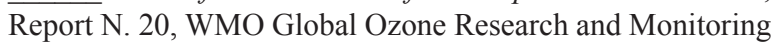
Project. Geneva, Switzerland: WMO, 1990.

Recebido em maio de 2010. Aceito em julho de 2010 . Publicado em dezembro de 2010. 